\title{
Evaluation of Ppiucd Insertion as a Method of Contraception in India
}

\author{
${ }^{*}$ Dr.Janki Patel ${ }^{1,}$ Dr.Rupa Vyas ${ }^{2,}$ Dr.SapanaShah ${ }^{3,}$ Dr.Purvi Parikh ${ }^{4}$ \\ ${ }^{1}$ Resident Doctor, ${ }^{2}$ Associate Professor, ${ }^{3}$ Professor \& Head Of The Unit, ${ }^{4}$ Assistant Professor \\ Dept. Of Obstetrics And Gynecology,Smt N.H.L. Municipal Medical College,Sheth V.S. General Hospital, Ellis \\ Bridge,Ahmedabad-16 \\ *Corresponding author: *Dr.Janki Patel1
}

\begin{abstract}
:
Aim: To evaluate and compare safety and efficacy of PPIUCD in two groups of patients: vaginal insertion group after normal delivery and intra cesarean insertion group.

Methods: A prospective study carried out in the Department of Obstetrics and Gynecology at a tertiary care center. After counseling with patients and her relatives during antepartum period, IUCD insertion was done in 1438 patients. In 417 patients IUCD was inserted vaginally. In 1021 patients IUCD was inserted while cesarean section. All these patients were followed up after 6 weeks and after 6 months interval regularly. All the complications were recorded and studied. Incidence, clinical outcome \& missing threads were analyzed.

Results: Both the methods of PPIUCD insertion were safe and efficacious. Out of 1438 women, 1340 cases had follow up as per the protocol. Fifty eight cases who lost for follow up and 40 cases who had spontaneous expulsion, were excluded from study. There were missing strings in 363 cases at 6 weeks examination and in 338 cases at 6 months follow up examination. Ultrasonography of pelvis establishes IUCD location in uterine cavity. Neither perforation nor pregnancy with PPIUCD was found in present study. They have low rates of abdominal pain, pelvic infection, heavy menstruation and lost strings.

Conclusion: PPIUCD is an appealing approach and may become a choice of post-partumcontraception. It is safe and effective method of reversible contraception.Missing strings after PPIUCD insertion is a common problem encountered during follow up examination. Every user must be followed up and provider must take better aftercare in forms of follow up and management of complication if needed.
\end{abstract}

Keywords: PPIUCD, vaginal insertion, intra cesarean insertion

\section{Introduction}

Rapid repeated and unwanted pregnancies result in adverse outcome for both mother and child. In India,61\% of births occur at intervals that are shorter than recommended birth to birth interval of 36 months. Twenty seven percent of births occur within 24 months after previous birth and $34 \%$ of births occur between 24 and 35 months. Only $26 \%$ of post-partum women are using any method of family planning during $1^{\text {st }}$ post-partum year. ${ }^{1}$ Sterilization is leading method of contraception in India, accounting for $40 \%$ of FP users. It does not address need of birth spacing.

Hence,immediate post-partum period is favorable time for counseling and addressing issue of birth spacing because women, who have given birth recently, are highly motivated to use contraception. Advantage should be taken for counseling on PPIUCD during post-partumperiod. It has major advantage over interval insertion as there is no need to confirm non pregnant status of woman and already they are in health care facilities. In developing countries like India, delivery is only opportunity when women come in contact with health care provider. They usually do not come for advice for contraception. Since 1975, China has been practicing immediate PPIUCD insertion. Scenario has been changed with the introduction of PPIUCD in several other countries.

The string of IUCD is used to locate the device in situ and also to remove device.Missing strings may be due to expulsions,curling and in drawing into uterine cavity,breaking,expulsion outside, uterine perforation and migration of device into the peritoneal cavity.Missing strings are common findings during PPIUCD follow up as compared to interval IUCD where it is really uncommon findings. During follow up of PPIUCD, every woman is advised pelvic ultrasound, if necessary, $\mathrm{X}$ ray abdomen.Invasive methods are required to retrieve displaced IUCD.It creates stress on part of client and provider as well which may be detrimental to program.

\section{Objective}

The aim was to study the incidence,management,clinical outcome of missing strings,rates of complications like infection, heavy menstrual bleeding,lower abdominal pain,rates of removal and to compare among two modes of insertion(after vaginal delivery \& intra cesarean insertion group). 


\section{Materials And Methods}

It was a prospective study conducted from January2015 to December2016 in the Department of Obstetrics and Gynecology at a tertiary care center.All eligible women fulfilling inclusion criteria were included for study.

\section{Inclusion Criteria:}

1. Post-partum mothers of any age in post placental period

2. Post-partum mothers within 48 hours of delivery

3. Cesarean section

\section{Exclusion Criteria:}

1. Mothers $>48$ hr.post-partum

2. Prolonged rupture of membrane

3. $\mathrm{PPH}$

4. HIV reactive patients

5. Anemia

6. PID

7. Knowncase of pelvic tuberculosis

8. Diabetes

9. Heart disease

10. Patients who did not want PPIUCD

Patients were explained regarding benefits and side effects of PPIUCD. Patients were also explained regarding other available methods of contraception.CuT380-A wasused. After proper counseling with patient and her relatives, CuT was placed by long Kelley's forceps touching fundus immediately after vaginal delivery using aseptic precautions(Post placental CuT insertion).Strings were not cut. Same procedure was done for patients who were willing for PPIUCD insertion within $48 \mathrm{hrs}$. In patients who required cesarean, CuT was inserted after delivery of placenta by sponge holding forceps high up to fundus followed by gentle with drawl of sponge holding forceps. Strings were put inside uterine cavity pointing towards cervical canal. Total 18,131patients werecounseled.Out of them, 1647patients were willing for $\mathrm{Cu} \mathrm{T}$ insertion. CuT insertion was done in 1438 patients. In 417 patients IUCD was inserted vaginally within 10 minutes of placenta removal and within 48 hours of delivery. In1021 cesarean sections IUCD was inserted following delivery of placenta.

Depending upon mode of delivery, they were divided in two groups: vaginal PPIUCD group and intra cesarean section PPIUCD group. Out of 1438 patients, 1340 patients had follow up as per protocol. 58 cases who lost for follow up(22 in vaginal group and 36 in intra cesarean group) and 40 cases who had spontaneous expulsion (28 in vaginal group and 12 in intra cesarean group), were excluded from study.Follow up of patients of both groups was done at 6 week interval. Follow up visits of patients were mainly focused on complaints of patients, confirmation of proper PPIUCD placement, per speculum examination for visibility of strings, pelvic ultrasound. Patients are advised to come at every 6 months interval for follow up. All information provided by this study groups were used for calculating statistics and tabulation of descriptive data was prepared.

\section{Results And Analysis}

In this study, it was found that second Para (49.54\%) patients accepted PPIUCD more than others.Patient of age group of 20-24(49.94\%) had the best acceptance of PPIUCD followed by 25-29 years(30.14\%).Patients from urban areas $(93.14 \%)$ had shown better acceptance than rural area patients.

\begin{tabular}{|l|l|}
\hline Age group(years) & $\begin{array}{l}\text { Total=1340 } \\
\mathrm{N}=(\%)\end{array}$ \\
\hline$<19$ & $31(2.32)$ \\
\hline $20-24$ & $669(49.94)$ \\
\hline $25-29$ & $404(30.14)$ \\
\hline $30-34$ & $166(12.42)$ \\
\hline $35-39$ & $54(4.01)$ \\
\hline $40-44$ & $16(1.16)$ \\
\hline
\end{tabular}

\begin{tabular}{|l|l|}
\hline Educational status & $\begin{array}{l}\text { Total=1340 } \\
\mathrm{N}=(\%)\end{array}$ \\
\hline No formal education & $167(12.41)$ \\
\hline Primary education & $533(39.71)$ \\
\hline Secondary education & $501(37.38)$ \\
\hline Higher secondary education & $75(5.60)$ \\
\hline Others & $64(4.78)$ \\
\hline
\end{tabular}


Evaluation of Ppiucd Insertion as a Method of Contraception in India

\begin{tabular}{|l|l|}
\hline Parity & $\begin{array}{l}\text { Total=1340 } \\
\mathrm{N}=(\%)\end{array}$ \\
\hline Para I & $471(35.18)$ \\
\hline Para II & $664(49.54)$ \\
\hline Para III & $170(12.67)$ \\
\hline Para IV & $33(2.45)$ \\
\hline Para V & $2(0.13)$ \\
\hline
\end{tabular}

\begin{tabular}{|l|l|}
\hline Residence & $\begin{array}{l}\text { Total }=1340 \\
\mathrm{~N}=(\%)\end{array}$ \\
\hline Urban & $1248(93.14)$ \\
\hline Rural & $92(6.85)$ \\
\hline
\end{tabular}

At 6 weeks follow up visit each and every patient showed proper placement of IUCD on USG.On per speculum examination at 6 weeks follow up,in $82.02 \%$ patients of vaginal group,strings were visible.In intra cesarean group, $69.5 \%$ patients had visible strings on per speculum examination. Missing strings were found in 363 patients at 6 weeks follow up (in $17.9 \%$ patients in vaginal group and in 30.5\% patients in intra cesarean group). At 6 months follow up missing strings were found in 338 patients (14.98\% in vaginal group and $29.08 \%$ in intra cesarean group).There was spontaneous descent of strings in 25 cases after 6 months. Heavy menstrual bleeding was complained by $9 \%$ patients of vaginal insertion group and by $6 \%$ patients of intra cesarean insertion group patients. No pregnancy was reported with $\mathrm{CuT}$ in situ in any group. Only $1 \%$ patients were presented with PID in both vaginal and cesarean group. Abdominal pain was complained by $5 \%$ patients of vaginal group and $4.5 \%$ patients of cesarean group patients. PPIUCD had to be removed in 84 women.Fifteen (4\%) following vaginal insertion and 69(7\%) following intra cesarean group.

PPIUCD had to be removed in $2 \%$ patients for vaginal bleeding in vaginal group and $1 \%$ in cesarean group. Abdominal pain was the cause for PPIUCD removal in intra cesarean insertion group for $2 \%$ patients and in vaginal group for $1 \%$ patients. Missing thread was reason for IUCD removal in $1 \%$ of patients in vaginal group and $4 \%$ patients in cesarean group though IUCD was in situ in USG.Total removal rate was $4 \%$ in vaginal group and $7 \%$ in cesarean group. Forty (2.9\%) cases of spontaneous expulsion of PPIUCD were reported.

\begin{tabular}{|l|l|l|l|}
\hline Reason for removal & $\begin{array}{l}\text { Vaginal group(367) } \\
\mathrm{N}=(\%)\end{array}$ & $\begin{array}{l}\text { Intra cesarean group(973) } \\
\mathrm{N}=(\%)\end{array}$ & $\begin{array}{l}\text { Total (1340) } \\
\mathrm{N}=(\%)\end{array}$ \\
\hline Bleeding P/V & $7(2)$ & $10(1)$ & $17(1.26)$ \\
\hline Abdominal pain & $4(1)$ & $19(2)$ & $23(1.71)$ \\
\hline Missing strings & $4(1)$ & $40(4)$ & $44(3.28)$ \\
\hline Total & $15(4)$ & $69(7)$ & $84(6.2)$ \\
\hline
\end{tabular}

\begin{tabular}{|l|l|l|l|}
\hline Complications & $\begin{array}{l}\text { Vaginal insertion group (367) } \\
\mathrm{N}=(\%)\end{array}$ & $\begin{array}{l}\text { Intra cesarean group } \\
(973) \\
\mathrm{N}=(\%)\end{array}$ & $\begin{array}{l}\text { Total (1340) } \\
\mathrm{N}=(\%)\end{array}$ \\
\hline Bleeding P/V & $33(9)$ & $58(6)$ & $91(6.79)$ \\
\hline Pregnancy & $0(0)$ & $0(0)$ & $0(0)$ \\
\hline Infection & $4(1)$ & $10(1)$ & $14(1.04)$ \\
\hline Abdominal pain & $18(5)$ & $44(4.5)$ & $62(4.62)$ \\
\hline Perforation & $0(0)$ & $0(0)$ & $0(0)$ \\
\hline
\end{tabular}

\begin{tabular}{|l|l|l|l|}
\hline & $\begin{array}{l}\text { Vaginal insertion group } \\
(367) \\
\mathrm{N}=(\%)\end{array}$ & $\begin{array}{l}\text { Intra cesarean group (973) } \\
\mathrm{N}=(\%)\end{array}$ & $\begin{array}{l}\text { Total (1340) } \\
\mathrm{N}=(\%)\end{array}$ \\
\hline $\begin{array}{l}\text { Missing strings at 6 } \\
\text { weeks }\end{array}$ & $66(17.98)$ & $297(30.52)$ & $363(27.08)$ \\
\hline $\begin{array}{l}\text { Missing strings at 6 } \\
\text { months }\end{array}$ & $55(14.98)$ & $40(4)$ & $338(25.22)$ \\
\hline $\begin{array}{l}\text { Removal of IUCD in case } \\
\text { of missing strings }\end{array}$ & $4(1)$ & $44(3.28)$ \\
\hline
\end{tabular}

\section{Discussion}

PPIUCD is safe and convenient option of contraception with no increased risk of infection, perforation or bleeding. ${ }^{2,3}$ Patients having more than two children had lower acceptance of IUCD among cesarean group than vaginal group.This may be due to willingness of such patients for permanent sterilization.PPIUCD acceptance was higher among parity2 and parity1, whereas, the study done by Safwat et al. in Egypt showed rate of 16\% PPIUCD acceptance inprimipara motherscompared to one third of multiparous. ${ }^{4}$ Acceptance is more in urban population $(93.14 \%)$ as compared to rural area.This difference may be due to higher education in urban area.

One of the disadvantage of PPIUCD is the high rate of expulsion,as after child birth uterus is contracting and cervix is dilated.Most of the expulsions occurwithin 3 months of delivery. When IUCD is inserted immediately 
postpartum, expulsion rate at 6 months ranged from 31 to 41 per 100 in a WHO multicenter trial. ${ }^{5}$ In present study, it was $6.7 \%$ in vaginal group and $1.1 \%$ in intra cesarean group with overall expulsion rate of 2.8\%.Expulsion is more common in vaginal group than intra cesarean group,it supports many studies worldwide. Expulsion rate of a prospective study by Halder A et al is $4 \%$ in vaginal insertion group and $2 \%$ in intra cesarean insertion group. ${ }^{6} \mathrm{Celen} \mathrm{S}$ et al in 2004 found that one year cumulative expulsion rate of CuT was $12.3 \%$ in early post-partum insertion of IUCD (vaginal group) and another study conducted by him in 2011 found $17.6 \%$ expulsion rate in intra cesarean IUCD. ${ }^{7,8}$

Most common reason for discontinuation is complain of missing stringsfollowed by heavy menstrual bleeding andabdominal pain. Pain in abdomen was complained by 5\% of the patients in vaginal group and $4.5 \%$ in intra cesarean group. Its coincides with study conducted byHalderA et al who reported abdominal pain in $5.5 \%$ of vaginal group and in $4 \%$ of intra cesarean group. ${ }^{6}$

In present study, pelvic infection rate (2\%) is same as compared to a study done in Kenya and Mali which indicated a rate of $2 \%$. All patients were examined for visibility of threads and proper placement of CuT at 6 weeks.Incidence of missing strings in present study was more common in intra cesarean group.IUCD strings were visible in $73 \%$ women at 6 week and in $74.8 \%$ women at 6 months.Bhutta et al reported visibility of $92 \% \& 96 \%$ at 6 months in intra cesarean group and interval insertion group respectively. ${ }^{9}$ Hooda $\mathrm{R}$ et reported $78 \%$ rate of visible strings in vaginal group and $45 \%$ rate in intra cesarean group. ${ }^{10} \mathrm{Curling}$ and retraction of thread in cervical canal and uterine cavity are major cause of missing strings.In present study ,removal of IUCD by simple pulling with artery forceps from uterine cavity was done in $59.5 \%$ under sedation. $35.7 \%$ cases required D \& $\mathrm{C}$ under short GA and $4.7 \%$ required hysteroscopy for removal of embedded IUCD.Sujnanendra M reported simple pulling of IUCD with artery forceps in $79.4 \%$ of cases,by D \& C in $18.8 \%$ cases and hysteroscopy in one case. ${ }^{11}$ In case of PPIUCD insertion, thread may take time to descent.Usually $75 \%$ of threads are visible by the end of 3 months.Contraceptive efficacy was same in both $\operatorname{group}(0$ per 100 women year).Failure rate of about 2-3 pregnancies per 100 women year has been described in case of interval IUCD insertion.Sujnanendra M reported $1.9 \%$ failure rate following PPIUCD. ${ }^{11}$

Pelvic ultrasound was done in all cases at 6 weeks follow up.In many cases USG was done more than once.No perforation was found in any group in present study.In case of PPIUCD insertion perforation is very rare,but it may occur with inexperienced and careless provider.Those who had intra caesarean insertion were more satisfied $(73 \%)$ with this method than vaginal delivery group $(66 \%)$ supported by study JishaBai C.P et al. ${ }^{12}$ In present study, PPIUCD was found to be very safe and effective method of contraception among both the groups similar to inference drawn by Cochrane Database review by Grimes et al. in $2010 .^{13}$

\section{Conclusion}

From this study,Itcan be concluded that PPIUCD is satisfactory approach as a post-partum family planning method irrespective of mode of delivery.PPIUCD is safe and reliable approach for spacing births and to meet unmet need of family planning.It has abundant scope in India.Insertion of CuT380A is a safe regarding expulsion rate. Both vaginal and cesarean insertions are safe in terms of complication and efficacious from contraception point of view.Only strings of IUCD after cesarean section are late to be visible at follow up.Most of the expulsions occur within 3 months of delivery.Missing strings after PPIUCD is a common problem encountered during follow up and invasive methods are needed for IUCD removal with non-visible strings. This issue is more common in intra cesarean group.In case of PPIUCD insertion,threads may take time to descend.Usually $75 \%$ of threads are visible by end of 3 months.Thus,PPIUCD is safe and better option as a contraception having no reported incidence of perforation and pregnancy and low rates of abdominalpain, pelvic infection, heavy menstruation and lost strings.In asymptomatic cases, if IUCD is in proper intrauterine location, then no further work up is necessary. Continuation rate was higher in cesarean section as compared to vaginal insertion.

\section{References}

[1]. Post-partum IUCD reference manual; Family Planning Division.Ministry of health and family welfare. Govt. ofIndia.2010:1:2

[2]. Mishra S. Evaluation of safety,efficacy, and expulsion of post-placental and intra-cesarean insertion of intrauterine contraceptive devices (PPIUCD) .J ObstetGynecol India.2014;64(5):337-43.doi:10.1007/s13224-014-0550-3.

[3]. Lopez-Farfan JA, Hernandez-Gonzalez A,Velez-machorroIJ,Vazquez-Estrada LA. A comparative, randomized study of levonorgestrel intrauterine system(LNG-IUS) vs copper T380A intrauterine device applied during cesarean section.Open J Obstet Gynecol. 2012;2(4):151-5.

[4]. Mohamed SA, Kamel MA, Shaaban OM, et al. Acceptability for the use of post-partum intrauterine contraceptive devices: assiut experience. Med PrincPract. 2003;12:170-5.

[5]. SingalS,Bharti R, Dewan R, et al.Clinical outcome of post-placental copper T380A insertion in women delivering by cesarean section.JClinDiagn Res.[serial online] 2014;8(9):OC04.

[6]. Halder A, Sowmya MS, Gayen A, Bhattacharya P, Mukherjee S, Datta S, et al.A Prospective Study to Evaluate Vaginal Insertion and Intra-Cesarean Insertion of Post-Partum Intrauterine Contraceptive Device. J ObstetGynaecol India. 2016 Feb;66(1):35-41.

[7]. Celen S, Moroy P, Sucak A, et al. Clinical outcomes of early post-placental insertion of intrauterine contraceptive devices. Contraception. 2004;69:279-82 
[8]. Celen S, Sucak A, Yildiz Y, et al. Immediate post placental insertion of an intrauterine contraceptive device during cesarean section. Contraception. 2011;84:240-3.

[9]. Bhutta SZ, Butt IJ,Bano K. Insertion of intrauterine contraceptive device at cesarean section. J CollPhysSurg Pak. 2011;21(9):52730 .

[10]. Hooda R, Mann S, Nanda S, et al.Immediate Postpartum Intrauterine Contraceptive Device Insertions in Caesarean and Vaginal Deliveries: A Comparative Study of Follow-Up Outcomes. Int J Reprod Med. 2016; 2016:7695847

[11]. Sujnanendra M Tale of the tails, the missing postpartum IUCD strings.The J of Obstetrics and Gynecology of India 2017;67(3):2027.doi 10.1007/s 13224-016-0940-9.

[12]. JishaBai C. P."A Study on the Complications of Immediate Post-Partum IUCD Insertion". Journal of Evidence based Medicine and Healthcare.2015; 9: 1246-51.

[13]. Grimes DA, Lopez LM, Schulz KF, et al. Immediate post-partum insertion of intrauterine devices, Cochrane Database Systemic Review 2010;12:CD003036 